\title{
Histórias de leves enganos e parecenças: a literatura subversiva de Conceição Evaristo
}

\author{
Wilma dos Santos Coqueiro ${ }^{1}$
}

doi.org/10.47585/nemtudosaorosas13 


\section{"Escrevo o que a vida me fala": Considerações iniciais}

Em “Odireito à literatura”, o grande crítico literário brasileiro Antonio Candido, concebe a literatura como um fator indispensável de humanização, por considerá-la "o sonho acordado das civilizações". Para ele, ela "confirma o homem em sua humanidade, inclusive porque atua em grande parte no subconsciente e no inconsciente" (2011, p. 175). Assim, na sua concepção, todas as pessoas, independente de raça ou classe social, deveriam ter direito a certos bens que são incompressíveis, ou seja, necessários, como casa vestuário, moradia, alimentação, saúde e amparo à justiça pública, assim como o direito à crença, ao lazer a resistência à opressão, e (por que não?) o direito à arte e, por extensão, à literatura, como "ler Dostoievski ou ouvir os quartetos de Beethoven" (CANDIDO, 2011, p.172).

Candido salienta que todas as formas e gêneros literários são importantes e têm papel formador, mas destaca a literatura social - tendência da qual faz parte Conceição Evaristo - como aquela que analisa o universo social e procura corrigir suas iniquidades. Como exemplo dessa literatura que apresenta posição social e humanitária, o autor destaca a poesia abolicionista do poeta romântico baiano Castro Alves (18471871), cuja obra "foi em parte um poderoso libelo contra a escravidão, pois ele assumiu posição de luta contribuiu para a causa que procurava servir" (CANDIDO, 2011, p. 181). Candido distingue também a importância do romance social de Vitor Hugo, Os miseráveis, publicado na França em 1862, como obra que coloca o pobre como protagonista da narrativa - cujos personagens eram, até então, invariavelmente da elite - focalizando suas mazelas e trazendo como um dos temas básicos "a ideia de que a pobreza, a ignorância e a opressão geram o crime" (CANDIDO, 1989, p. 183).

Ainda segundo o crítico, em terras brasileiras, a representação do pobre, embora tenha havido presenças esparsas na ficção naturalista do século XIX, só ganhara relevo no decênio de 1930 com os romances de autores como Jorge Amado, Graciliano Ramos e Rachel de Queiroz, entre outros. Para Candido, nessa literatura de tonalidade social, "o homem do povo com todos os seus problemas passou a primeiro plano e os escritores deram grande intensidade ao tratamento literário do pobre" (CANDIDO, 2011, p. 185). Essa literatura de "desmascaramento social" caracteriza a ficção de Evaristo, cujo cenário das periferias é repleto de personagens que têm suas vidas marcadas pela violência, pela miséria e pela opressão.

Bárbara Araújo Machado (2014), em seu artigo "Escre(vivência): a trajetória de Conceição Evaristo", ao traçar um pouco da trajetória pessoal e literária da autora, chama a atenção para as origen pobres da escritora mineira, nascida em uma favela em Belo Horizonte, em 1946, seu ingresso no magistério e seu envolvimento no Movimento Negro, quando radicou-se no Rio de Janeiro, o que lhe possibilitou que escrevesse de forma a retratar o universo negro com tanta propriedade e preocupação social. Machado destaca ainda que a autora mineira sempre declara, em entrevistas, que sempre teve consciência de ser negra e que essa consciência também está ligada à condição de classe, uma vez que "as mulheres de sua família sempre trabalharam como empregadas domésticas para importantes escritores/ as mineiros como Otto Lara Resende, Alaíde Lisboa de Oliveira e Henriqueta Lisboa “ (MAHADO,2014, p. 247). Essas relações de classe, também lhe propiciam a consciência de subalternidade - a autora também trabalhou como doméstica desde os oito anos de idade - o que também comparece em sua literatura. Para Evaristo, conhecer Carolina Maria de Jesus, a mulher negra e favelada que publicou a comovente obra O quarto de despejo, em 1960, sobre as agruras vividas na favela, e foi traduzida para vários idiomas, significou muito na sua constituição como escritora:

Quando mulheres do povo como Carolina, como minha mãe, como eu também, no dispomos a escrever, eu acho que a gente está rompendo com o lugar que normalmente no é reservado. A mulher negra, ela pode cantar, ela pode dançar, ela pode cozinhar, ela pode se prostituir, mas escrever, não, escrever é alguma coisa... é um exercício que a elite julga que só ela tem esse direito. Escrever e ser reconhecido como um escritor ou como escritora, aí é um privilégio da elite. (EVARISTO apud MACHADO, 2014, p. 249). 
Ao trilhar a vida acadêmica, com doutorado concluído em 2011, em literatura comparada, pela Universidade Federal Fluminense, a autora, estreia na literatura com o poema "Vozes-Mulheres", publicado em 1990, na coletânea Cadernos negros, o que marca sua filiação na Literatura Negra Brasileira. Quando publica o romance Ponciá Vicêncio, por uma editora pequena, a Mazza, a escritora teve que bancar a publicação com recursos próprios. Algo semelhante ocorreu em 2011, quando publicou a coletânea de contos Insubmissas lágrimas de mulheres, pela editora Nandyala, e teve que bancar $60 \%$ dos custos da publicação. Isso mostra que, mesmo sendo uma autora de destaque no cenário nacional, com livros traduzidos para outras línguas, é estranho que a autora tenha, até recentemente, que custear suas publicações, ocupando uma posição marginalizada no campo editorial da Literatura Brasileira. Para Machado, "essa situação revela o lugar de gueto que a literatura negra ainda ocupa dentro do campo editorial amplo, bem como a posição problemática da literatura negra em relação à literatura brasileira." $\left(2014\right.$, p. 260) ${ }^{3}$

Já em seu livro O que é lugar de fala?, a filósofa feminista Djamila Ribeiro traz discussões relevantes acerca do feminismo negro para abordar como escritores/as negros/as podem falar sobre as realidades vivenciadas pelos seus grupos sociais e raciais. Desse modo, o lugar de fala não se refere a uma voz individual, mas sim expressa uma coletividade, pois considera a expressão de grupos sociais, buscando dar visibilidade àqueles historicamente excluídos e reconhecimento aos seus discursos / às suas vozes. Segundo a autora:

A nossa hipótese é que a partir da teoria do ponto de vista feminista, é possível falar de lugar de fala. Ao reivindicar os diferentes pontos de análise e a afirmação de que um dos objetivos do feminismo negro é marcar o lugar de fala de quem as propõem, percebemos que esta marcação se torna necessária para entendermos realidades que foram consideradas implícitas dentro da normatização hegemônica. (RIBEIRO, 2019, p. 61-2).
Nesse sentido, as considerações de Ribeiro contribuem para analisarmos alguns contos selecionado de Conceição Evaristo e seu percurso na literatura, pois mostra que grupos socialment excluídos - como o das mulheres negras - começam a se ver em lugares privilegiados - no caso, no espaço acadêmico e no mercado editorial- e a reivindicarem que suas vozes sejam ouvidas. Desse modo, a visibilização do lugar de fala propõe a pluralidade dos pontos de vista, descontruindo a ideia de um discurso único - de um sujeito masculino, branco, heterossexual e cristão - que por muito tempo predominou no universo literário, constituindo o cânone das obras clássicas que são consideradas como as únicas dignas de serem lidas e valorizadas como patrimônio cultural.

A coletânea de contos Histórias de leves enganos e parecenças, corpus de reflexão desse trabalho, foi publicada em 2016 e é composta por doze contos e um novela, que abordam um universo povoado por personagens negras - em sua maioria mulheres - que sofrem diferentes formas de opressão e violência, mas que buscam afirmar suas subjetividades. Embora a coletânea traga elementos discursivos e temáticos recorrentes em outras coletâneas, como Insubmissas lágrimas de mulheres (2011) e Olhos d’água (2014), ela traz elementos inovadores na ficção evaristiana ligados ao insólito e ao imprevisível.

\section{"A vida está para além do que pode ser visto, dito ou escrito": as subjetividades femininas autênticas na ficção evaristiana}

A coletânea de contos Histórias de leves enganos e parecenças, publicada originalmente em 2016, uma obra marco em um ano de grandes conturbações políticas, traz uma galeria de personagens femininas bastante diversas entre si. Essas personagens que sofrem diversos tipos de opressão, geralmente advinda de critérios como raça, classe e gênero, também são capazes de impor

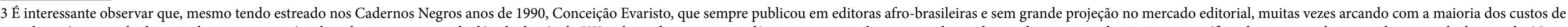

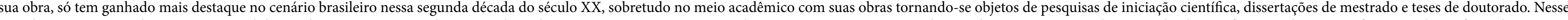

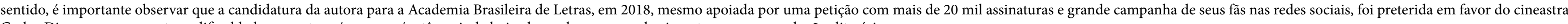
Carlos Diegues, o que mostra a dificuldade que autores/as negros/as têm, ainda hoje, de receberem reconhecimento por suas produções literárias.

4 Fragmento da apresentação da autora à coletânea História de leves enganos e parecenças (EVARISTO, 2017, p. 17). 
suas vontades e de fazer valer suas vozes. Em uma prosa sutil e elegante, uma das marcas apontadas pelos críticos acerca da obra de Evaristo, em contos cuja marca temporal nem sempre é identificada, a escritora mineira matiza experiências femininas, cuja marca é a resistência, sobretudo ligada à corporeidade, à memória e à ancestralidade.

Em uma obra em que se sobressai posturas éticas e humanitárias, sem cair no tom doutrinário, as personagens femininas agem de forma responsiva em seu embate com uma sociedade misógina, racista e profundamente desigual. De acordo com a professora Assunção de Maria Souza e Silva, no posfácio ao livro, "os contos de Conceição são contos-personagens que se realizam pelas falas dos personagens no ato de rememorar a prática do cotidiano que, por sua vez, remetem à condição étnica dos gêneros" (SILVA, 2017, p. 107). A crítica ainda pontua aspectos importantes na urdidura da narrativa evaristiana que é a figura do narrador-ouvinte. Para Silva, o fato de as narradoras, geralmente mulheres, exercerem "a função de ouvinte e de contadora da história alheia que não deixa de ser também histórias de si mesmas" (SILVA, 2017, p. 110), o que aponta para a ideia de empatia e sororidade feminina.

Embora vários contos tragam nuances que oscilam entre a sutileza e a brutalidade do mundo, protagonizados por mulheres autênticas e combativas, nesse trabalho, o foco de análise recai em dois contos que mostram diferentes formas de subjetividades femininas. Tanto em "A moça de vestido amarelo" quanto em "A menina e a gravata" comparecem personagens jovens em processo de formação humana, identitária e cultural.

De acordo com Silva (2017), nessa coletânea, "Conceição toma a decisão de percorrer a seara do insólito, do estranho, do imprevisível” (p. 104). São essas incursões por situações insólitas que, aos moldes da literatura fantástica, tendem a provocar hesitação nos leitores. Contudo, Silva enfatiza que nos contos evaristianos, o insólito não de caracteriza da mesma forma que nas obras fantásticas ocidentais. Nesse sentido, os acontecimentos estranhos que comparecem nos contos parecem apontar para um "realismo animista", termo que Pepetela, escritor africano, cunhou para caracterizar algumas narrativas africanas.
Isto porque a existência da atuaç̃o de forças da natureza, da alteração dos fenômenos que modificam a ordem natural das coisas, a crença em entidades capazes de intervir na rotina dos personagens, etc. são estratégias concebidas por um modus operandi revelador da maneira de pensar, de ser e de existir de uma dada comunidade, cujas origens advém da diáspora africana. (SILVA, 2017, p. 106).

De fato, no conto "A moça do vestido amarelo", em que ocorre a mistura de rituais católicos e africanos, a presença do insólito está ligada à atuação de forças da natureza, que caracteriza esse "realismo anímico". A garota Dóris da Conceição Aparecida, em uma de suas primeiras falas, teria balbuciado a palavra "a-ma-e-lo". Como se sabe, essa cor relacionada ao sol e ao ouro, geralmente simboliza alegria, riqueza e fertilidade. Para Chevalier e Gheerbrant, essa é "a mais expansiva e mais ardente das cores, difícil de atenuar e que extravasa sempre dos limites em que o artista desejou encerrá-la" (CHEVALIER; GHEERBRANT, 2009, p. 40).

À medida que decorre a história, o simbolismo do amarelo ligado à divindade da religião iorubá Oxum - orixá das águas doces, e que representa a riqueza, a beleza e a fecundidade feminina - vai ficando mais evidente nas atitudes da menina que coloria todos seus desenhos dessa cor e, aos sete anos, sonha com a moça de vestido amarelo. Esses fatos, desapercebidos pela família católica da menina, só é vislumbrado pela avó que "sabia muito bem de que moça a Sãozinha estava falando" (EVARISTO, 2017, p. 23). Para os demais parentes, "a moça que enfeitava os sonhos da menina, só podia ser a Santa em suas diversas aparições de ajuda e milagres: Senhora Aparecida, Senhora Conceição, Senhora do Rosários dos Pretos, Senhora Desatadora de Nós, Nossa Senhora dos Remédios, a Virgem de Fátima" (EVARISTO, 2017, p. 24).

Ao ser informado dos sonhos da menina, o padre que realizaria sua Primeira Comunhão - ritual de passagem católico de iniciação à Eucaristia, quando os/as adolescentes obtêm o direito de receber "o corpo e o sangue de Cristo", materializado na hóstia sagrada - é breve e preciso ao responder que "deixasse estar, cada qual sonha com o que está guardado no inconsciente. E no inconsciente nem a força do catecismo, da pregação e nem as do castigo apagam tudo" (EVARISTO, 2017, p. 24). Nesse sentido, o padre recupera a teoria freudiana acerca do inconsciente humano como um local de leis próprias, onde predominam as 
pulsões que fogem ao controle das instituições repressoras. Para Freud, há formas de tradução do conteúdo inconsciente para o consciente e uma dessas formas de acesso ao conteúdo reprimido do inconsciente seria por meio dos sonhos ${ }^{5}$, que se configuram como uma espécie de realização de um desejo. De acordo com ele, "Podemos, portanto, legitimamente dizer o que quer que o sonho possa nos oferecer, ele obtém seu material da realidade e da vida psíquica centrada sobre essa realidade" (FREUD, s.d., p. 20).

A presença do insólito ocorre justamente no momento da comunhão, quando o rosto da menina se ilumina, revelando a força da ancestralidade e da espiritualidade das religiões de matriz africana, com a aparição de Oxum - a moça do vestido amarelo que aparecia nos sonhos da menina - materializada na água que transcorre pela igreja:

Uma luz intensa amarela brilhava sobre ela. E a menina se revestiu de tamanha graça, que a Senhora lá do altar sorriu. Uma paz, nunca sentida, inundou a igreja inteira. Ruídos de água desenhavam rios caudalosos e mansos a correr pelo corredor central do templo. E a menina em vez de rezar a Ave-Maria, oração ensaiada por tanto tempo, cantou outro cumprimento. Cantou e dançou como se tocasse suavemente as águas serenas de um rio. Alguns entenderam a nova celebração que ali acontecera. A avó de Dóris sorria feliz. Dóris da Conceição Aparecida, cantou para nossa outra Mãe, para nossa outra Senhora. (EVARISTO, 2017, p. 24-5).

Com efeito, a garota com dois nomes oriundos do panteão católico, "Conceição" e "Aparecida", impõe sua voz e legitima a ancestralidade herdada da avó ao, em um local sagrado do catolicismo, dançar e entoar cântico à Mamãe Oxum. Dessa forma, há uma afirmação da subjetividade negra de Dóris, autenticada pela inundação inusitada da água, símbolo da orixá africana, na igreja. A respeito do significado da água, elemento recorrente na ficção de Evaristo, Chevalier e Gheerbrant apontam "três temas dominantes: fonte da vida, meio de purificação, centro de regenerescência" (CHEVALIER; GHEERBRANT, 2009, p. 40). Na religião iorubá, Oxum, rainha das águas doces, tem sua história ligada às águas, elemento de sua importância não apenas no culto dos Orixás, mas também para a vida no planeta: "Para os yorubás, Oxum é a responsável pelo "líquido amniótico" (água que envolve o bebê no ventre materno) e dona do rio Òsun em Òsogbo, na Nigéria" (OXALÁ, 2012, n.p.). Nesse sentido, a inundação da água no ritual de iniciação cristã da menina aponta para esse resgate ancestral da personagem, como também para a purificação e pacificação sentidas na igreja.

Outro conto bastante emblemático dessa coletânea é o conto "A menina e a gravata". Em tempos de crescimento de uma onda conservadora no país, que propõe que "meninos usem azul e meninas usem rosa", a trajetória, em poucas páginas, da singular jovem Fémina Jasmine, desde a infância até a maturidade, é bastante empoderadora. A menina que se sentia fascinada por gravatas, ainda muito pequena, e que, aos quatro ou cinco anos, pediu para usá-las, causava estranheza e preocupação nos pais essa obsessão por uma "peça pontiaguda" que traz em si uma imagem fálica.

Fémina, já mocinha, nunca deixara de demonstrar sua audaciosa predileção por esse charmoso detalhe daqueles que se postavam perto dela. E diante da peça pontiaguda dos distraído homens, espadas penduradas nos peitoris dos cavalheiros, Fémina os agarrava tenazmente, pela sedutora peça do vestuário. (EVARISTO, 2017, p. 27).

Assim, a garota que passou "sua meninice em constante estado desejante, a juventude e quem sabe a vida inteira também” (EVARISTO, 2017, p. 28), realiza, afinal, seu desejo de portar uma gravata em seu vestuário apenas quando é matriculada em uma escola militar, aos dez anos, e pode, enfim, usar o uniforme com uma gravata preta que todas as outras fariam de tudo para não usar: "A menina se aquietou. E assim foram os seus dias na escola. Fémina se sentia confortável e segura enquanto as outras meninas odiavam o uniforme. (EVARISTO, 2017, p. 28).

É relevante observar que a feminilidade da garota, implícita no nome "Fémina", também se 
revela na sua trajetória pessoal, pois ela se apaixona por um dos meninos mais bonitos da escola, formando com ele "o casal ébano da histórica associação 'Lírio Negro"' (EVARISTO, 2017, p. 28), ocasião em que amigos e familiares "puderam contemplar a beleza de Fémina. Ela se apresentou enfeitada por uma gravata branca, que sobressaía por entre seus longos dreads, espalhados por suas costas e ombros" (EVARISTO, 2017, p. 28). Nesse sentido, sobressai-se a sensibilidade da autora ao eleger como protagonista do conto uma garota bonita, sensível, que assume seus traços étnicos e que, por gostar de uma peça da indumentária masculina ou ter atitudes viris, não deixa de ter sua feminilidade destacada. A sua subjetividade se impõe no modo como ela decide sobre a sua vida, em suas relações afetivas e na forma ousada de se apresentar no dia do seu casamento:

Entretanto, a imagem mais bonita de Fémina e suas gravatas surgiu no dia de seu casamento. Túlio Margazão seguia de terno branco, da mesma cor do vestido da noiva. A alvura do vestido da noiva era enfeitada por aplicações de minúsculas e coloridas gravatas-borboletas. E não teve a tradicional jogada de buquê. Sim, não teve! As moças presentes que tivessem o desejo de encontrar seu par foram convidadas a se aproximarem de Fémina, e cada qual podia arrancar uma borboleta do vestido da noiva. E assim fizeram. (EVARISTO, 2017, p. 28-9).

Nesse conto, também temos a presença do insólito quando algumas gravatas-borboletas do vestido voam, propiciando que as garotas mais reservadas, que não queriam revelar seus desejos matrimoniais publicamente, pudessem apanhá-las. E ao final do conto, ocorre a revelação de que "dizem mesmo que nenhuma das mulheres que colheu as gravatas borboletas de Fémina Jasmine ficou sozinha. Todas encontraram seus pares" (EVARISTO, 2017, p. 29). Isso mostra a aposta empoderadora da autora em uma celebração do amor entre personagens negras, imprimindo um happy ending à narrativa, bastante raro em textos ficcionais de autoria negra e com personagens negros/as.

Nos contos analisados, pode-se observar que, assim como explica Djamila Ribeiro, "existe um olhar colonizador sobre os corpos negros" (RIBEIRO, 2019, p. 39), o que corrobora a afirmação da feminista e ativista americana bell hooks ${ }^{6}$ de que a mulher negra "carrega todo o fardo da opressão sexista, racista e de classe" (hooks, 2019, p. 45). Contudo, pode-se observar que Evaristo transforma esse corpo negro em fonte de vida e de libertação de padrões estereotipados, ao criar figuras femininas intensas, combativas e resistentes à opressão de que são vítimas, seja da igreja, seja do patriarcado e seus vários tentáculos de dominação. Nesse sentido, pode-se concluir que as protagonistas dos dois contos analisados apresentam uma "subjetividade ativa”, termo criado pela socióloga e feminista argentina María Lugones (2014), em "Rumo a um feminismo decolonial"7 , para designar a resistência feminina às múltiplas formas de opressão. De acordo com essa ativista, "Em nossas existências colonizadas, racialmente gendradas e oprimidas, somos também diferentes daquilo que o hegemônico nos torna. Esta é uma vitória infrapolítica" (LUGONES, 2014, p. 940). É justamente o que se pode afirmar das personagens evaristianas dos contos analisados: ao resistirem à opressão para se enquadrarem em um ideal religioso ou feminino, forçado pela hierarquia social, eles se tornam diferentes do que as forças hegemônicas impõem como padrão, angariando, assim, existências autênticas.

\section{Considerações finais}

A feminista estadunidense bell hooks (2019) afirma a importância de se pensar no movimento feminista como um compromisso político. Dessa forma, rejeita-se a ideia de um feminismo como um mero estilo de vida pois, para ela, "trata-se de uma forma de resistência que nos engaja numa práxis revolucionária (hooks, 2014, p. 62). Essa também é a proposição do feminismo decolonial de Lugones, que entende a descolonização do 
gênero como uma práxis, na qual se decreta "uma crítica da opressão de gênero racializada, colonial e capitalista heterossexualizada, visando uma transformação vivida do social (LUGONES, 2014, p. 940).

Nesse sentido, a escritora negro-brasileira Conceição Evaristo, com sua literatura de tonalidade social, não se furta desse compromisso político ao criar heroínas que, apesar das situações de fragilidade, de opressão e de desigualdade em que estão imersas, conseguem se impor, construir suas subjetividades e resistir à ordem hegemônica opressora, para a qual se conjugam fatores como gênero, raça e classe.

A potência da narrativa evaristiana, que se impõe com força estética e ideológica na coletânea Histórias de leves enganos e parecenças, está na subversão ao cânone e às suas tradições balizadas por séculos de patriarcado, no enfrentamento às regras sociais impostas e na afirmação da identidade negra. Em histórias, marcadas pela oralidade e pela poeticidade - marcas estilísticas próprias da autora, que faz da memória um artifício na criação de suas histórias moldadas por suas vivências personagens femininas, herdeiras da diáspora africana, reivindicam seus lugares de fala, assim como o direito ao amor, à ancestralidade a à afirmação de suas subjetividades negras.

\section{Referências}

CANDIDO, Antonio. O direito à literatura. In: . Vários escritos. 5 ed. Rio de. Janeiro: Ouro sobre Azul; São Paulo: Duas Cidades, 2011.

CHEVALIER, Jean; GHEERBRANT, Alain. Dicionário dos Símbolos: (mitos, sonhos, costumes, gestos, formas, figuras, cores, números). Tradução Vera da Costa e Silva. 24. ed. Rio de Janeiro: José Olympio, 2009.

EVARISTO, Conceição. Histórias de leves enganos e parecenças. 5.ed. Rio de Janeiro: Malê, 2017.
FREUD, Sigmund. A interpretação dos sonhos: Partes I e II. Tradução de Constantino Korovaeff. São Paulo: Escala, s.d.

HOOKS, Bell. Teoria feminista: da margem ao centro. Tradução de Rainer Patriota. São Paulo: Perspectiva, 2019.

LUGONES, Maria. Rumo a um feminismo decolonial. Tradução de Juliana Watson e Tatiana Nascimento In: Estudos Feministas, Florianópolis, 22(3): 320, setembro-dezembro/2014. p. 935-952.

MACHADO, Bárbara Araújo. Escre(vivência): a trajetória de Conceição Evaristo. História Oral, v. 17, n. 1, p. 243-265, jan./jun. 2014.

OXALÁ, Paulo de. Água, o Axé de todos. In: Extra. 22 março de 2012. Disponível em: <https://extra. globo.com/noticias/religiao-e-fe/pai-paulo-de-oxala/agua-axe-de-todos-4380368.html\#: :text=Oxum\%20 tem\%20toda\%20a\%20sua,Òsun\%20em\%20Òsogbo\%2C\%20na\%20Nigéria>. Acesso em: 30 mar. 2021.

RIBEIRO, Djamila. O que é lugar de fala? 1.ed. São Paulo: Pólen Livros, 2019.

SILVA, Assunção de Maria Souza e. A fortuna de Conceição - Posfácio. In: EVARISTO, Conceição. Histórias de leves enganos e parecenças. 5.ed. Rio de Janeiro: Malê, 2017. 



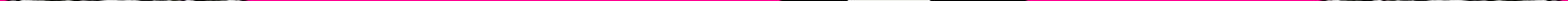

